\title{
Anti-Atherogenic Properties of Extra Virgin Olive Oil
}

\author{
Hidekatsu Yanai
}

Extra virgin olive oil (EVOO) is an important constituent of the Mediterranean diet as well as whole grains, vegetables, fruits and nuts. Recent meta-analysis showed that compared to low polyphenol olive oil, high polyphenol EVOO significantly improved measures of malondialdehyde, oxidized low-density lipoprotein (LDL), high-density lipoprotein-cholesterol (HDLC), inflammatory markers and blood pressure [1], suggesting significant anti-atherogenic effects of EVOO.

In a randomized, double-blinded, placebo-controlled clinical trial (RCT), 41 adult women with excess body fat received daily high-fat breakfasts containing $25 \mathrm{~mL}$ of soybean oil (control group, $\mathrm{n}=20$ ) or EVOO (EVOO group, $\mathrm{n}=21$ ) during nine consecutive weeks [2]. Fat loss was about $80 \%$ higher on EVOO compared to the control group $(-2.4 \pm 0.3$ kg vs. $-1.3 \pm 0.4 \mathrm{~kg}, \mathrm{P}=0.037)$. EVOO also reduced diastolic blood pressure when compared to control $(-5.1 \pm 1.6 \mathrm{~mm} \mathrm{Hg}$ vs. $+0.3 \pm 1.2 \mathrm{~mm} \mathrm{Hg}, \mathrm{P}=0.011)$.

The RCT was conducted on 60 already diagnosed cases of type 2 diabetes and dyslipidemia [3]. EVOO showed 8-12\% increase in HDL-C. EVOO has been also reported to promote cholesterol efflux by HDL, improving HDL functionality [4]. EVOO consumption reduced the age-related decrease in HDL and paraoxonase-1 anti-inflammatory activities [5]. EVOO intake increased HDL-C and decreased total cholesterol (TC)/ HDL-C and triglyceride (TG)/HDL-C in postmenopausal women [6].

Thirty impaired fasting glucose (IFG) patients were randomly allocated to a meal containing or not $10 \mathrm{~g}$ of EVOO in a cross-over design [7]. Before, $60 \mathrm{~min}$ and $120 \mathrm{~min}$ after lunch, a blood sample was taken. EVOO was associated with a reduction of glucose $(\mathrm{P}=0.009)$ and dipeptidyl-peptidase-4 (DPP4) activity $(\mathrm{P}<0.001)$ and a significant increase of insulin $(\mathrm{P}<$ $0.001)$ and glucagon-like peptide-1 (GLP-1) $(\mathrm{P}<0.001)$. Furthermore, the meal containing EVOO showed a significant decrease of TG $(\mathrm{P}=0.002)$ and Apo B-48 $(\mathrm{P}=0.002)$ compared with the meal without EVOO. EVOO use was also associated with improved post-prandial blood glucose and LDL-C in healthy subjects [8].

Habitual consumption of EVOO has been also reported to improve endothelial function in patients with prediabetes and diabetes [9]. Further, the systematic review on beneficial

Manuscript submitted April 22, 2018, accepted March 20, 2019

Department of Internal Medicine, National Center for Global Health and Medicine Kohnodai Hospital, 1-7-1 Kohnodai, Ichikawa, Chiba 272-8516, Japan. Email: dyanai@hospk.ncgm.go.jp

doi: https://doi.org/10.14740/jem509w effects of EVOO, and in conjunction with the Mediterranean style diets, reported that EVOO improved inflammation, oxidative stress, coagulation, platelet aggregation, fibrinolysis, and endothelial function [10].

In conclusion, although EVOO may have possible antiatherogenic properties, the real beneficial effects of EVOO on human health need to be clarified in new well-designed clinical studies.

\section{Conflict of Interest}

The author declares that he has no conflict of interest concerning this article.

\section{References}

1. George ES, Marshall S, Mayr HL, Trakman GL, TatucuBabet OA, Lassemillante AM, Bramley A, et al. The effect of high-polyphenol extra virgin olive oil on cardiovascular risk factors: A systematic review and metaanalysis. Crit Rev Food Sci Nutr. 2018:1-24.

2. Galvao Candido F, Xavier Valente F, da Silva LE, Goncalves Leao Coelho O, Gouveia Peluzio MDC, Goncalves Alfenas RC. Consumption of extra virgin olive oil improves body composition and blood pressure in women with excess body fat: a randomized, doubleblinded, placebo-controlled clinical trial. Eur J Nutr. 2018;57(7):2445-2455.

3. Khan TM, Iqbal S, Rashid MA. Comparison of lipid lowering effect of extra virgin olive oil and atorvastatin in dyslipidaemia in type 2 diabetes mellitus. J Ayub Med Coll Abbottabad. 2017;29(1):83-86.

4. Berrougui H, Ikhlef S, Khalil A. Extra virgin olive oil polyphenols promote cholesterol efflux and improve HDL functionality. Evid Based Complement Alternat Med. 2015;2015:208062.

5. Loued S, Berrougui H, Componova P, Ikhlef S, Helal O, Khalil A. Extra-virgin olive oil consumption reduces the age-related decrease in HDL and paraoxonase 1 anti-inflammatory activities. Br J Nutr. 2013;110(7):1272-1284.

6. Anderson-Vasquez HE, Perez-Martinez P, Ortega Fernandez $\mathrm{P}$, Wanden-Berghe $\mathrm{C}$. Impact of the consumption of a rich diet in butter and it replacement for a rich diet in extra virgin olive oil on anthropometric, metabolic and lipid profile in postmenopausal women. Nutr Hosp. 2015;31(6):2561-2570.

7. Carnevale R, Loffredo L, Del Ben M, Angelico F, No- 
cella C, Petruccioli A, Bartimoccia S, et al. Extra virgin olive oil improves post-prandial glycemic and lipid profile in patients with impaired fasting glucose. Clin Nutr. 2017;36(3):782-787.

8. Violi F, Loffredo L, Pignatelli P, Angelico F, Bartimoccia $\mathrm{S}$, Nocella C, Cangemi R, et al. Extra virgin olive oil use is associated with improved post-prandial blood glucose and LDL cholesterol in healthy subjects. Nutr Diabetes. 2015;5:e172.
9. Torres-Pena JD, Garcia-Rios A, Delgado-Casado N, Gomez-Luna P, Alcala-Diaz JF, Yubero-Serrano EM, Gomez-Delgado F, et al. Mediterranean diet improves endothelial function in patients with diabetes and prediabetes: A report from the CORDIOPREV study. Atherosclerosis. 2018;269:50-56.

10. Yubero-Serrano EM, Lopez-Moreno J, Gomez-Delgado F, Lopez-Miranda J. Extra virgin olive oil: More than a healthy fat. Eur J Clin Nutr. 2018. 